\title{
Centro Regional de Hemoterapia
}

\author{
Dimas Tadeu Covas \\ Diretor do Hemocentro de Ribeirão Preto
}

\section{HISTÓRICO}

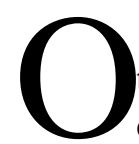
projeto de implantação do Hemocentro de Ribeirão Preto, enquanto Centro de Referência, teve início em agosto de 1987, ocasião em que, por convocação do Centro de Vigilância Sanitária, foram reunidos na Secretaria de Estado da Saúde, representantes das Macros-regiões de Saúde do Estado. Naquela oportunidade, foi estipulado o prazo de um mês, para que os membros das regiões apresentassem um diagnóstico sobre a situação da Hemoterapia, nas suas respectivas áreas de abrangência. Solicitou-se, ainda, a elaboração de um projeto para criação e implementação de Centros Regionais de Hemoterapia.

Em nossa região, foi constituída uma comissão para estudar a matéria e formular a proposta de implementação de um Hemocentro para Ribeirão Preto e Região. A comissão consultou o Hospital das Clínicas de Ribeirão Preto sobre o interesse em sediar o referido projeto já que o Serviço de Hemoterapia do Hospital das Clínicas era o que estava melhor estruturado.

O Hospital das Clínicas manifestou-se favorável e a partir daí o Serviço de Banco de Sangue e Hemoterapia do HCRP passou a funcionar com a responsabilidade de Centro de Referência (Hemocentro),

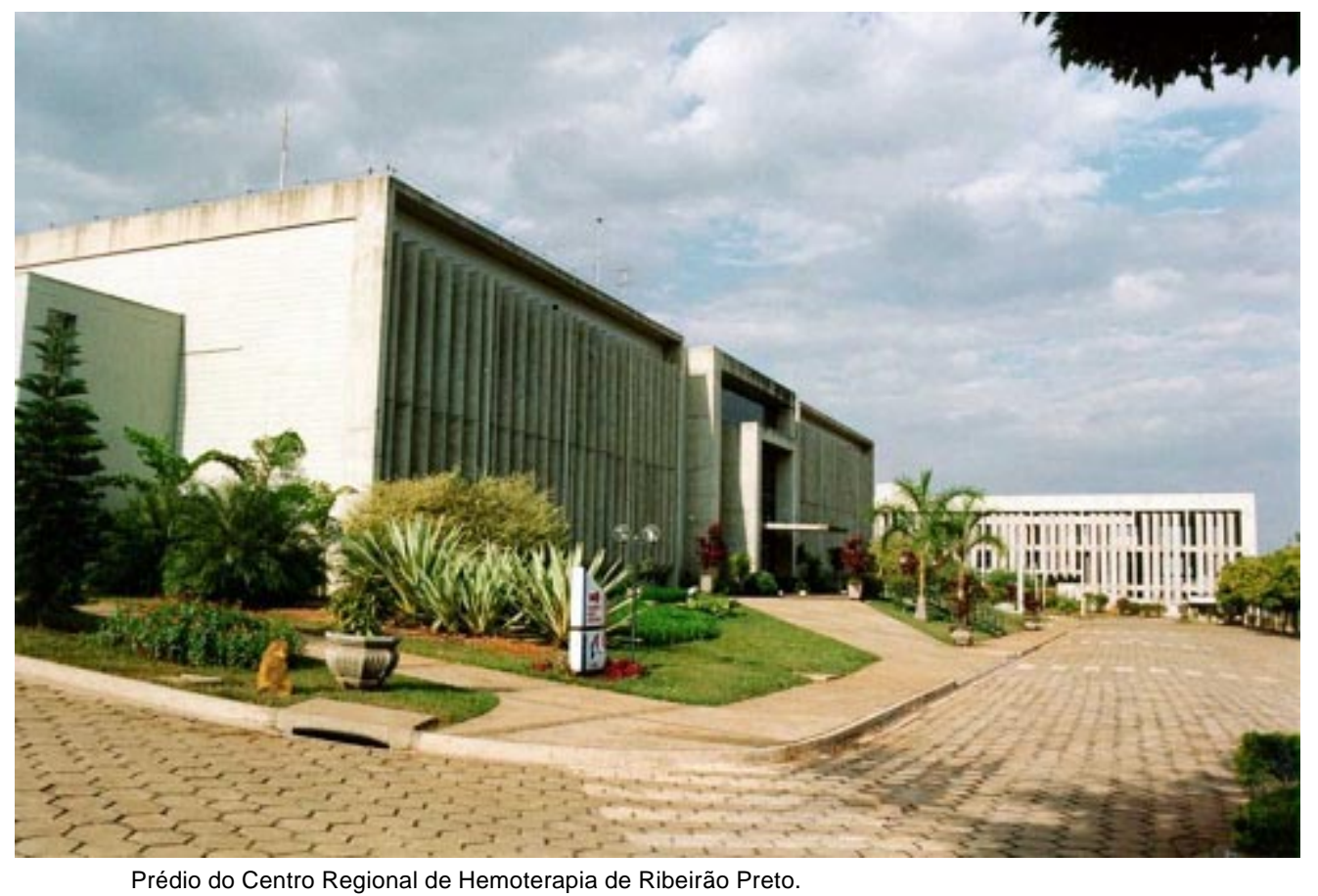


recebendo equipamentos do Ministério da Saúde e da Secretaria de Estado da Saúde. Porém, os recursos humanos mostravam-se insuficientes para atender à demanda regional na realização dos exames sorológi$\cos$, o que tornou a situação insustentável. O referido hospital não podia contratar pessoal, por força governamental. Em decorrência, a Secretaria de Estado da Saúde lotou profissionais, suprindo, assim, as necessidades, àquela situação emergencial.

Paralelamente, era necessária a expansão da área física e instalações para o funcionamento do Hemocentro. Algumas adaptações foram projetadas e concretizadas, porém o Programa previa muito mais. Não sendo possível sua expansão, passou-se a estudar um projeto de construção de uma unidade nas imediações do prédio do Hospital das Clínicas. Após vários entendimentos, estabeleceu-se a área física, situada na confluência da Rua Tenente Catão Roxo e Av. Norte, pertencente ao Campus Universitário da USP. O projeto arquitetônico foi desenvolvido e as obras tiveram início durante o ano de 1990 e foram concluídas em 1994.

Resolvido, no nível das metas, o problema da área física e de construção da sede, tornou-se necessária a revisão da estrutura funcional, representada, então, pelo Serviço de Banco de Sangue e Hemoterapia do HCRP e que não era compatível com as necessidades e atribuições de um Hemocentro. Após estudos detalhados, empreendida pela Assessoria Técnica do HCRP e Grupo Técnico do Serviço, formulou-se uma proposta de compatibilização da estrutura existente com as novas necessidades e realidades. Apresentado o projeto ao Governo do Estado de São Paulo, foi aprovada, através do Decreto n 39.509 , de 11/11/94 a criação do Centro Regional de Hemoterapia, ligado ao Hospital das Clínicas da Faculdade de Medicina de Ribeirão Preto da Universidade de São Paulo, e a da Fundação Hemocentro de Ribeirão Preto, para dar apoio necessário ao programa.

\section{MODELO GERENCIAL ATUAL}

O Plano Nacional do Sangue e Hemoderivados, preconizado pelo Ministério da Saúde, recomenda que as estruturas organizacionais dos hemocentros ofereçam a necessária flexibilidade e autonomia administrativa e financeira, e sejam capazes de possibilitar seu bom funcionamento, com o máximo de eficiência e eficácia.
É através de tal estrutura e parceria que a Fundação Hemocentro de Ribeirão Preto tem levado avante o programa, na Região Norte do Estado.

\section{3. ÁREA GEOGRÁFICA DE ABRANGÊNCIA E POPULAÇÃO-ALVO}

O Hemocentro de Ribeirão Preto atua em uma região com 213 municípios e aproximadamente 4,3 milhões de habitantes. através de uma rede de 4 Núcleos de Hemoterapia - Araçatuba, Fernandópolis, Franca e Presidente Prudente - 5 Unidades de Hemoterapia - Altinópolis, Batatais, Bebedouro, Olímpia e Serrana - 5 Agências Transfusionais e 1 Posto de Coleta, além de sua unidade central, integrados por um moderno sistema de informática.

A Hemo-Rede na região, está hierarquizada em: Agência Transfusional Campus, Agência Transfusional de Franca, Agência Transfusional de Jales, Agência Transfusional de Santa Fé do Sul, Agência Transfusional Sta. Casa de Ribeirão Preto, Agência Transfusional Unidade de Emergência, Hemocentro, Núcleo de Hemoterapia de Araçatuba, Núcleo de Hemoterapia de Fernandópolis, Núcleo de Hemoterapia de Franca, Núcleo de Hemoterapia de Presidente Prudente, Posto de Coleta Unidade de Hemoterapia de Batatais, Unidade de Hemoterapia de Bebedouro, Unidade de Hemoterapia de Olímpia, Unidade de Hemoterapia de Serrana.

Paralelamente à atividade assistencial hemoterápica, o Hemocentro de Ribeirão Preto desenvolve um intenso e consistente programa de pesquisa como parte do CTC, Centro de Terapia Celular, atuando nas áreas de Hemoterapia, Hematologia, Transplante de Medula Óssea, Biologia Molecular e Celular, voltadas para as doenças do sangue e infecções.

Além disso, o Hemocentro promove, permanentemente atividades de treinamento de recursos humanos, ensino e divulgação das informações resultantes de suas atividades junto à comunidade científica e à população em geral, agilizando a disseminação dos conhecimentos e a transferência dos resultados das pesquisas desenvolvidas para a sociedade, reiterando sua meta de cumprir, com seriedade e determinação, o papel social que lhe é atribuído.

A equipe de 400 funcionários é formada por médicos, biologistas, pesquisadores, enfermeiros, fisioterapeutas, dentistas, psicólogos, técnicos e auxiliares de laboratório, assistentes sociais, captadores de doadores e administradores. 
O Hemocentro conta hoje com cerca de 100 mil doadores cadastrados em toda a região de cobertura, e desenvolve diversos mecanismos de incentivo à permanência e regularidade das doações, através do acesso à informação pela população, por meio de campanhas de comunicação e programas educativos e motivacionais, com cursos, palestras e vídeos, obtendo uma média de 8.000 doações/mês, com um movimento anual médio de 5.800 atendimentos nos ambulatórios de Hemostasia, Hemoglobinopatia, Trombofilias, Transplante de Medula Óssea e Investigação de Paternidade

O Hemocentro desenvolve ainda campanhas de doação, regionais e participa de eventos de âmbito nacional, como a Semana do Doador e o Programa Nacional de Doação Voluntária de Sangue; promove coletas externas, visando à manutenção do estoque necessário, para suprir com qualidade a demanda de sangue e derivados em todos os hospitais situados na sua área de abrangência, bem como desenvolve a cultura da doação de sangue

Investindo em novas instalações, o Hemocentro acaba de concluir um moderno anexo administrativo, além de um grande anfiteatro. Encontra-se em fase final de construção o Biocentro, que concentrará as unidades de pesquisa e desenvolvimento em Biotecnologia Aplicada à Hematologia, Hemoterapia, Oncologia e Imunologia.

\section{ASSISTÊNCIA}

A reorganização da rede pública de doação de sangue, com a criação da Hemo-Rede/SP, reduziu sensivelmente o risco de contaminação por HIV e de transmissão de outras doenças contagiosas através do sangue. Esse resultado vem sendo obtido através de campanhas de educação dos candidatos à doação e de um permanente e rigoroso processo de triagem, avaliação e análise do sangue coletado.

Inserido nesse contexto, o Hemocentro de Ribeirão Preto apresenta o mais alto padrão de excelência e confiabilidade nos procedimentos e produtos derivados do sangue, além de oferecer serviços especializados de Fisioterapia e Odontologia para pacientes transplantados, hemofílicos e portadores de anemias hereditárias.

Além disso, o Serviço Social do Hemocentro oferece apoio psicossocial a pacientes transplantados e a doadores com sorologia alterada, colabora nos ambulatórios de Hemostasia e Hemoglobinopatias e desenvolve o trabalho de captação de doadores de medula óssea.

\section{O CAMINHO DO SANGUE}

Segurança e eficiência no atendimento à população.

Razão de ser do Hemocentro, a rotina de captação, processamento e armazenamento de sangue e hemocomponentes é realizada sob rigorosos cuidados, desde a seleção dos doadores, os ensaios sorológicos e imunoematológicos, a conservação e a armazenagem, até sua utilização em transfusões e outros procedimentos hemoterápicos.

Um moderno sistema informatizado garante total controle sobre o sangue coletado, permitindo a identificação e o encaminhamento médico de eventuais doadores com sorologia positiva, resultando na total confiabilidade dos hemocomponentes produzidos.

O Hemocentro de Ribeirão Preto desenvolve ainda atividades de assistência e pesquisa em terapia celular, principalmente no que diz respeito à manipulação de células progenitoras do sangue, destinadas a transplantes em pacientes com doenças oncoematológicas. Para isso, essas células, coletadas por aférese, são conservadas em baixíssimas temperaturas, em tanques de nitrogênio líquido, no Laboratório de Criobiologia, até o momento de sua utilização. Esse procedimento permite tanto a conservação de células coletadas do próprio paciente para uso em transplantes autólogos, como a preservação de células de sangue placentário (sangue do cordão umbilical), destinadas a transplantes alogênicos, não consangüíneos.

Com o intuito de ampliar o atendimento a pacientes portadores de doenças oncoematológicas, foi implantado um Banco de Sangue do Cordão Umbilical, através de um programa de seleção de doadoras e coleta de material em 2 maternidades de Ribeirão Preto, contando com apoio de pesquisa do $\mathrm{CNPq}$, no valor de $\mathrm{R} \$ 202 \mathrm{mil}$.

O Hemocentro oferece ainda tratamentos especializados de Fisioterapia e Odontologia.

O serviço de Fisioterapia, voltado para hemofílicos, portadores de anemias hereditárias e pacientes transplantados de medula óssea, trabalha os aspectos motores e respiratórios dos pacientes, melhorando seu condicionamento físico e garantindo seu bem estar físico e emocional.

O serviço de Odontologia, especializado em hemofílicos, portadores da doença de von Willebrand e outras doenças hereditárias, caracterizadas por distúrbios da coagulação, é o único da região. É gratuito e realiza tratamentos preventivo, convencional, restaurador e cirúrgico, em pacientes de todas as idades. 


\section{QUALIDADE GARANTIDA}

Em 1997, o Hemocentro iniciou, com o apoio financeiro da FINEP - Financiadora de Estudos e Projetos - a implementação do Sistema de Garantia de Qualidade, visando à padronização de todos os procedimentos realizados, desde a coleta de sangue, fracionamento, criobiologia, ensaios sorológicos e imunoematológicos até os procedimentos terapêuticos e de transfusão, além do armazenamento e distribuição dos produtos hemoterápicos.

Esse processo, envolvendo o detalhamento de todos os Procedimentos Operacionais e Técnicos, Métodos de Ensaio, a criação de um Laboratório de Controle de Qualidade e de um Setor de Manutenção, culminou com a obtenção, em novembro de 1999, da certificação ISO 9002, garantindo o cumprimento dos requisitos de segurança e eficiência em todos os processos e produtos gerados pelo Hemocentro, de acordo com padrões internacionais.

O Hemocentro de Ribeirão Preto foi o primeiro hemocentro público do país a contar com a totalidade de suas operações certificados.

Dentro desse enfoque, o de "garantia de qualidade", o Hemocentro, em parceria com a Secretaria Estadual da Saúde, tem o apoio do programa de Políticas Públicas da FAPESP, no desenvolvimento e implantação de um software destinado a avaliar, técnica e gerencialmente, os serviços de hemoterapia da região de abrangência do Hemocentro de Ribeirão Preto. Esse projeto estará sendo estendido para os Hemocentros do Estado de São Paulo.

\section{IMUNOEMATOLOGIA}

No Laboratório de Imunoematologia, $o$ sangue doado é classificado através da tipagem $\mathrm{ABO}$ e fatores $\mathrm{Rh}$, presença de anticorpos contra glóbulos vermelhos e presença de hemoglobina S, evitando-se reações indesejáveis no paciente receptor durante a transfusão de hemocomponentes. Através da tipagem do sangue para outros sistemas sanguiíneos diferentes do $\mathrm{ABO} / \mathrm{Rh}$, é também possível manter doadores de sangues raros, que podem ser usados em pacientes crônicos.

\section{SOROLOGIA}

O sangue é analisado para detectar os vírus de AIDS (HIV), Hepatite B $e$ HTLV $1 e$ II, Sífilis e Do- ença de Chagas, através de testes específicos e altamente confiáveis, utilizando equipamentos de última geração, permanentemente avaliados e certificados pelo Ministério da Saúde.

\section{FRACIONAMENTO}

Laboratório de Fracionamento, Estoque e Distribuição: as bolsas de sangue são submetidas a um processo de centrifugação, que resulta na separação dos hemocomponentes - concentrado de hemácias, plasma fresco, crioprecipitado e concentrado de plaquetas - permitindo atender às necessidades específicas de cada paciente.

\section{PESQUISA}

O Hemocentro de Ribeirão Preto é parte integrante do CTC - Centro de Terapia Celular - que integra as atividades de núcleos de pesquisa, instalados no Campus da USP de Ribeirão Preto, desenvolvendo trabalhos nas áreas de Biologia Molecular, Hematologia e Química de Proteínas. Na área de Química de Proteínas conta com o apoio do CNPq, no valor de $\mathrm{R} \$ 150 \mathrm{mil} / \mathrm{ano}$, por 5 anos.

Contando com laboratórios de Biologia Molecular e Celular, Análise de Genoma, Criobiologia, Citometria de Fluxo e Bioinformática, aparelhados com equipamentos de última geração, os pesquisadores do Hemocentro desenvolvem um intenso trabalho de pesquisa, relativo às propriedades das células e suas modificações, visando à criação de instrumentos de tratamento no campo da terapia celular.

Selecionado como um dos 10 centros de excelência dentre 112 projetos de instituições de pesquisa do Estado, o CTC faz hoje parte do programa de Centros de Pesquisa, Inovação e Difusão CEPID - lançado pela FAPESP para apoiar instituições que realizam pesquisas multidisciplinares na fronteira do conhecimento, com uma verba anual de R \$ 1,3 milhão, durante 5 anos. O programa prevê mecanismos para rápida transferência de tecnologia e difusão dos resultados obtidos para a sociedade, através de parcerias com o setor privado, contribuindo para o desenvolvimento de novas tecnologias e para a criação de novas empresas, e com órgãos públicos, como foco gerador de políticas públicas na área de saúde, além da difusão dos conhecimentos adquiridos junto ao meio científico e ao sistema educacional. 


\section{TERAPIA CELULAR}

\subsection{Um Campo em Rápida Expansão}

Transfusão de componentes do sangue, transplantes autólogos e alogênicos de medula óssea e de sangue do cordão umbilical são os exemplos mais importantes da rápida expansão do campo da terapia celular. Além disso, novas técnicas de coleta, cultura e modificação de material genético celular tornam possível manipular populações de células para aumentar seu potencial terapêutico.

O principal foco de pesquisa do CTC são os mecanismos celulares básicos - diferenciação celular, interações celulares, mediadores celulares, proliferação celular, apoptose, inflamação e coagulação e o processamento de células - isolamento, seleção, expansão e purificação - aspectos relevantes para a terapia celular.

As diversas pesquisas atualmente em andamento contemplam tópicos como: doenças genéticas trombofilias, hipercolesterolemia, fenilcetonúria, anemias e talassemia - virologia, leucemias, transplante de células hematopoéticas, terapia gênica e genoma do câncer.

Em parceria com o Instituto de Química da USP, o Hemocentro vem, também, desenvolvendo pesquisa para produção do Fator VIII da coagulação por tecnologia de DNA Recombinante, com apoio da FINEP, Financiadora de Estudos e Projetos, no valor de R $\$ 1,9$ milhão de reais.

Além disso, o Hemocentro já desenvolveu e tem patenteado um kit para diagnóstico da Doença de Chagas, e estão em adiantado processo de desenvolvimento kits para diagnóstico de HIV e HTL.

\section{BIOINFORMÁTICA}

O processamento da informação a serviço da ciência.

Contando com técnicos em Ciência da Computação, Análise de Sistemas, Processamento de Dados e Biomedicina, o laboratório de Bioinformática do Hemocentro dá suporte à toda atividade de pesquisa, realizando trabalhos, como a montagem e análise de seqüências e o desenvolvimento de bancos de dados relacionais.

Tem participado em inúmeros projetos, implementados em conjuntos com outros laboratórios, como a decodificação do material genético da drosophila melanogaster e da apis melífera, pela metodologia
Orestes, além de desenvolver metodologias próprias para incrementar o desempenho do laboratório nos trabalhos de mapeamento de DNA e possibilitar a troca de informações com outros bancos de dados.

Faz parte da CompBioNet, rede virtual em Bioinformática, criada no ano 2000 para acelerar as análises das sequiências geradas pelo Projeto Genoma do Câncer Humano.

\section{XYLELLA FASTIDIOSA}

\subsection{Sucesso e reconhecimento}

O projeto denominado Genoma da Xylella fastidiosa, nome da bactéria que causa o "amarelinho" em frutas cítricas, foi concluído com sucesso, obtendo grande repercussão na comunidade científica mundial, colocando o Brasil em destaque nas principais publicações do meio científico.

O Hemocentro participou da rede de 32 laboratórios (Rede ONSA), coordenada pela FAPESP, que realizou o seqüenciamento completo dessa bactéria. Isso permitiu a aquisição de experiência, além do desenvolvimento de novas áreas e de novos projetos, como o Genoma do Câncer Humano.

\section{CÂNCER, UMA DOENÇA DOS GENES}

Pesquisa nas fronteiras do conhecimento.

Um dos principais projetos de alta tecnologia em desenvolvimento pelo Centro de Terapia Celular visa a estudar as características dos genes ativos ou alterados nos tumores malignos, abrindo perspectivas para diagnósticos mais precisos e formas mais eficazes de tratamento da doença.

Tal atividade teve início com a participação do Hemocentro no Projeto Genoma do Câncer Humano, que consistiu no mapeamento genético de células derivadas de câncer, utilizando recursos da ordem de R $\$ 580$ mil anuais, subvencionado pela FAPESP, Fundação de Amparo à Pesquisa do Estado de São Paulo, em parceria com o Ludwig Institute for Cancer Research. A utilização da tecnologia Orestes, desenvolvida no Brasil o segundo maior colaborador (em quantidade) de seqüências de DNA de tumores, no GenBank, o banco de dados internacionais de sequiências genéticas.

Dando continuidade, além do estudo das características dos genes de leucemias, linfomas e melanomas, o projeto visa avaliar o envolvimento de fatores imunológicos e abordagens terapêuticas novas, como a manipulação de células e genes (Terapia Genética). 


\section{ENSINO}

\subsection{Formação, Treinamento e Difusão}

Desde sua criação, o Hemocentro de Ribeirão Preto desenvolve um extenso e permanente programa educacional, que inclui o treinamento de profissionais da saúde (médicos, enfermeiros, fisioterapeutas, técnicos de laboratório e biologistas), treinamento de especialistas e pesquisadores, incluindo mais de 75 bolsistas entre estudantes de pós-graduação médica, residentes em Hematologia e Hemoterapia e alunos de graduação, além do treinamento de professores do Ensino Secundário e programas de fomento ao ensino da ciência, em escolas de nível médio.

O Hemocentro promove diversas atividades educacionais, que incluem cursos teóricos e práticos, projetos de pesquisa para estudantes e professores do nível médio, minicongressos, exposições e competições, organização e publicação dos resultados de pesquisas e colaboração com professores na organização de museus e bibliotecas virtuais e na produção de vídeos, material impresso e CDs para uso em computadores.

Em 1992, foi criada a Escola Brasileira de Hematologia, apoiada pelo Hemocentro, com o objetivo de promover a educação continuada de médicos, nas áreas de Hematologia e Hemoterapia, trazendo grandes benefícios não só na experiência científica, mas, especialmente, na prática clínica. Desde sua criação, foram treinados cerca de 470 profissionais.
A implementação do CTC, Centro de Terapia Celular, promoveu a expansão dessas atividades e a criação de novos projetos, como o desenvolvimento de programas de iniciação científica, seminários, cursos de verão e treinamento em nível de doutorado e pós-doutorado, incorporando, ainda, mecanismos de transferência contínua do conhecimento básico e aplicado à medida em que é gerado. Outra característica é o contínuo redirecionamento de suas atividades para atender às demandas da sociedade através da interação de seus pesquisadores e profissionais com o setor produtivo e com o governo através de seminários, palestras e simpósios.

As atividades educacionais do Hemocentro incluem o oferecimento de cursos visando à formação de especialistas em Biologia Molecular, em nível de mestrado e doutorado, e uma intensa colaboração com o ensino médio, para dar oportunidade de acesso a alunos e professores aos conhecimentos nas áreas de Genoma, Genética, Imunologia, Citologia e Educação em Saúde, através do projeto denominado As Células, o Genoma e Você, Professor. Este programa educativo compreende várias estratégias para divulgação, incluindo um portal na lnternet, permitindo à comunidade o acesso a temas como Aids e outras doenças transmitidas pelas transfusões, tratamento do Câncer e de Leucemia, doação e transfusão de sangue, transplante de medula óssea e de outros órgãos e genoma humano. 